\title{
Fracasos en Sicoprofilaxis *
}

\author{
ESTUDIO DE 80 CASOS \\ Dr. Miguel A. Fernéndez-Bastidas
}

E.M.E.S.F.A.O.+

$\mathrm{Al}$ continuar el estudio iniciado hace algún tiempo sobre las causas de fracaso en la aplicación de la sicoprofilaxis en obstetricia (1) nos proponemos analizar tales causas valiéndonos del estudio detenido de un grupo de pacientes atendidas en la Clínica Palermo de Bogotá.

Reafirmando que la forma de lograr un mayor campo de aplicación del método, es propender a su perfeccionamiento, presentamos de acuerdo con nuestra clasificación de fracasos, el análisis de ellos a fin de corregir los errores, disminuyendo al máximo en un futuro las causas que los producen.

\section{MATERIAL Y METODO}

Las historias son las correspondientes a ochenta pacientes privadas, entrenadas y atendidas por EMESFAO en la Clínica Palermo de Bogotá, y cuyos resultados fueron juzgados rígidamente como fracasos. (2) (3) (4) (5).

Vale la pena aclarar que tales pacientes, a pesar de haberse beneficiado con el método "estaban inconcientes y anestesiadas en el período expulsivo". Igualmente vale la pena anotar que hubo casos en que en una misma paciente se presentaron varias causas de descondicionamiento siendo raro el caso de causa única definida. Por tal motivo no pudiéndose valorar las causas de manera individual la suma de muchas de estas causas, rebasa la de éstos.

\footnotetext{
* Trabajo presentado al III Simposio de Sicoprofilaxis. Bucaramanga 1961.

+ Equipo Médico de Estudios Sicofísicos de Analgesia Obstétrica de Bogotá.
} 
SICOPROFILAXIS OBSTETRICA

CAUSAS DE FRACASO

I - Causas debidas al experimentador

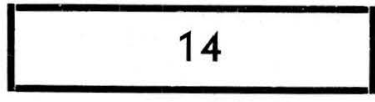

1 Falta de apoyo del médico

\section{CUADRO No 1}

\section{COMENTARIO}

En este parágrafo pcdemos deducir que los beneficios del apoyo durante el trabajo son de importancia capital; catorce casos no vigilados por la instructora por hallarse ésta prestando su colaboración en otro caso, se descondicionaron y fracasaron en su gran mayoría por dolor y especialmente por temor incontrolable.

El obstetra tuvo la culpa del fracaso tan solo en uno de los casos por imposibilidad de dar a la paciente el apoyo suficiente con su presencia e indicaciones, por tener al mismo tiempo otras en las mismas condiciones.

\section{CAUSAS DE FRACASO}

II - Causas debidas a condiciones ambientales
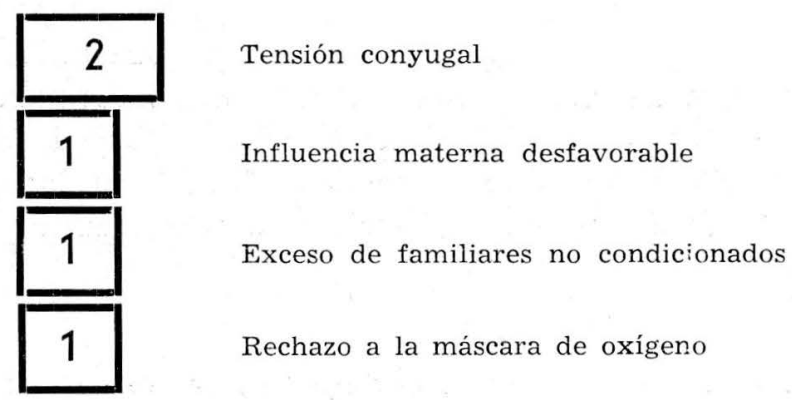
II Causas debidas a condiciones ambientales (cuadro № 2)

Si bien dimos una importancia excepcional a ésta causa de fracaso en nuestra primera comunicación, (1) al ser más estrictos en el análisis de las condiciones ambientales desfavorables, tan solo las hallamos claras en cinco casos de fracasos. Dos de tales casos fueron por problemas conyugales y los restantes por una influencia traumatizante de la madre de la embarazada, por exceso de familiares descondicionantes durante el parto 0 por rechazo a la máscara de oxígeno.

\section{CAUSAS DE FRACASO}

III - Causas debidas a las condiciones de vida de la paciente

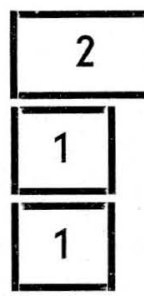

Problemas familiares

Relaciones sexuales prematrimoniales

Rechazo conciente al embarazo

\section{CUADRO No 3}

III Condiciones de vida de la paciente (cuadro № 3)

Bajo este numeral solamente agrupamos cuatro casos; dos por problemas familiares, y uno por trauma producida por relaciones sexuales prematrimoniales y parto aparentemente prematuro ,y otro por un rechazo franco conciente al embarazo instaurado en una gran multípara de definidas tendencias neuróticas. 
CAUSAS DE FRACASO

IV - Causas Intrinsecas

a) Obstétricas

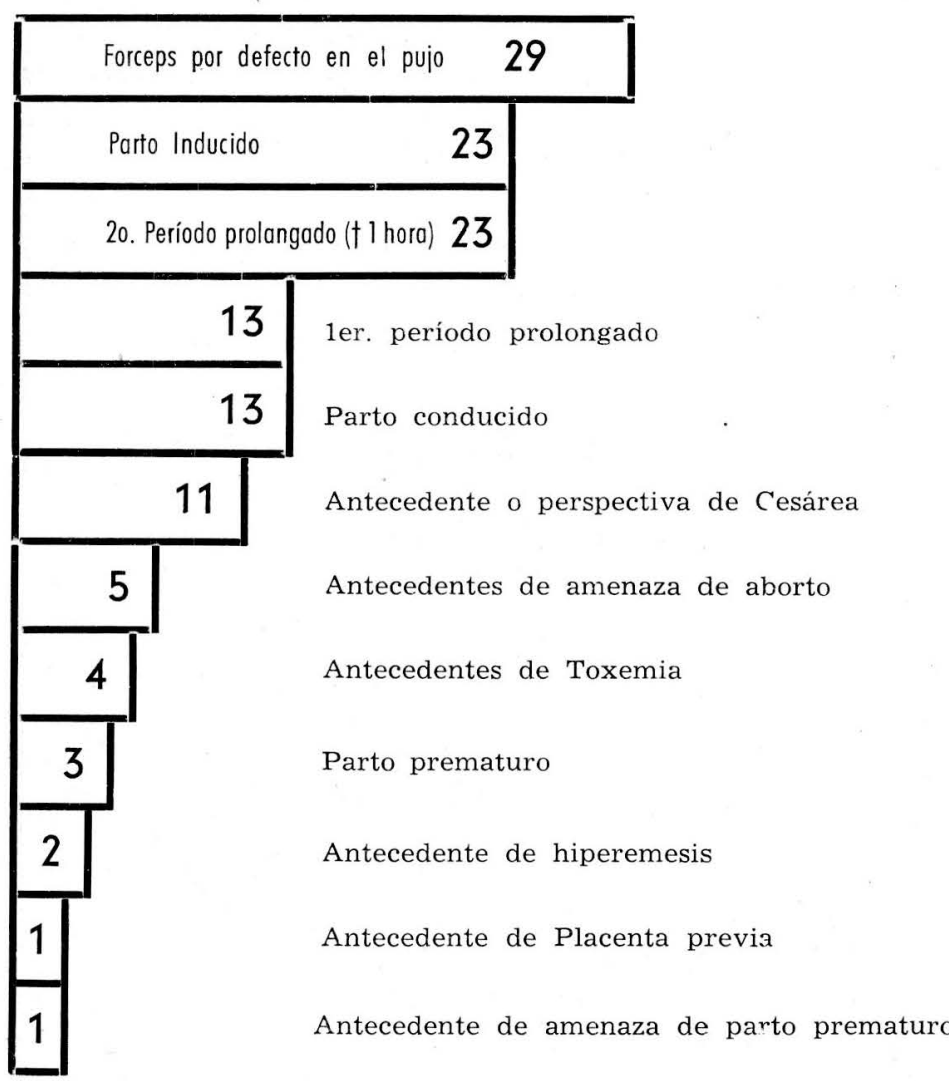

CUADRO No 4

IV Causas intrinsecas

a) Obstétricas (cuadro $\mathrm{N}^{\circ} 4$ )

A pesar de haberse podido aplicar fórceps sin anestesia en no pocos casos referidos de sicoprofilaxis (5) señalamos ésta intervención verificada bajo anestesia como causa de fracaso, pues todos los 29 casos anotados tuvieron una indicación absoluta que en su mayoría fue la falla en la rotación y descenso, casos en los cuales el pujo habría fracasado. 
Las causas obstétricas que en orden de frecuencia merecen destacarse son: inducción (por producir en pacientes no bien preparadas gran sensación de temor,; antecedentes o perspectivas de cesárea, casos en los cuales la paciente presentó verdaderas crisis de angustita; 13 conducciones (posiblemente por goteos rápidos de ocitocina trastornaron la dinámica uterina); 0 causas presentes durante el embarazo como la toxemia, la hiperemesis, la placenta previa, o las amenazas de aborto o de parto prematuro.

\section{CAUSAS DE FRACASO \\ IV - Causas Intrínsecas}

b) Sicológicas

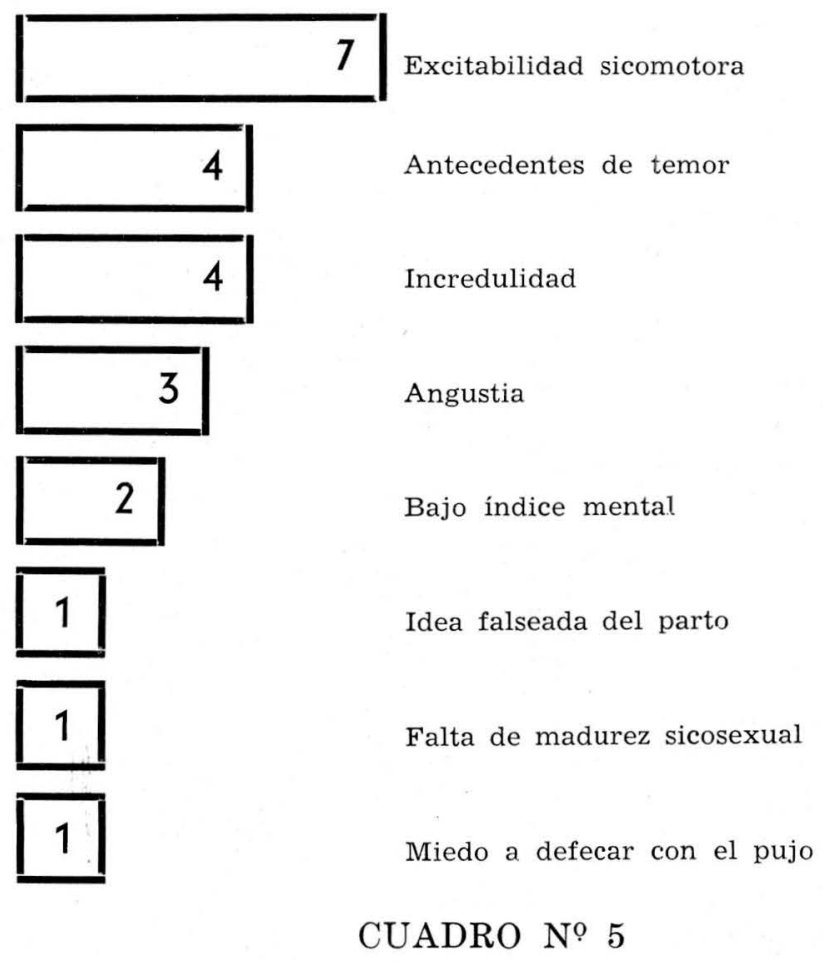

b) Causas Sicológicas (cuadro $\mathrm{N}^{0} 5$ )

Independientes del tipo nervioso o perfil caracterológico, (6) tenemos causas de fracaso intrínsecas ligadas íntimamente con el factor sicológico. En los casos analizados encontramos en 
primer término la excitabilidad y luego el temor, pese a la preparación, casos explicables solamente por un grado tan superlativo de angustia que la preparación no alcanzó a neutraizar; además encontramos 4 casos de pacientes cuyo escepticismo por los beneficios del método impidió en forma absoluta su condiciorumiento. Además de las causas anteriores encontramos estados de angustia posiblemente incontrolables por sicoprofilaxis y susceptibles de una sicoterapia más profunda; por último como causas menos frecuentes: el bajo nivel intelectual, la falta de maduración sicosexual y un caso interesante que se presentó en una primigestante cuyo condicionamiento se perdió al sentir contracciones bastante activas durante el parto que la hicieron manifestar posteriormente en su informe: "tenía la idea de que el parto no podria ser doloroso"; desde tal experiencia procuramos insistir más en la colaboración activa de la paciente para llegar a obtener un estado total completo de indolorización, gracias al bloqueo cortical.

Causas de fracaso

IV -- Causas Intrínsecas

c) Físicas

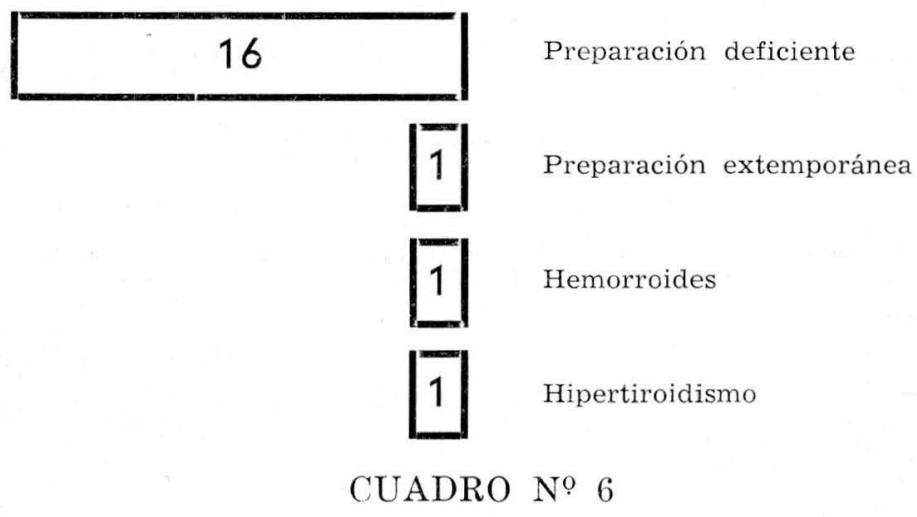

c) Causas físicas (cuadro No 6)

Entre las causas de orden físico las principales son las relacionadas con la preparación.

De acueráo con lo establecido en el Primer Simposio de Sicoprofilaxis (7) una preparación no puede ser sino buena o ma- 
la no aceptando un grado intermedio. Dicha calificación la podemos graduar por medio de la asistencia a clases teóricas y prácticas cuya constancia aparece en el carnet que al matricularse lleva cada señora; como puede observarse en el cuadro $\mathrm{N}^{0} 6$ un número relativamente grande de casos (16) tuvieron una mala preparación. Solo un caso de preparación extemporánea llegó a ser fracaso, pero es necesario aclarar que por tratarse de pacientes de excepción en nuestras series no podríamos todavía concluír nada en concreto; quedan así en último lugar las hemorroides y el hipertiroidismo como causales menos frecuentes de descondicionamiento. Por último las causas relacionadas con tipos nerviosos las cuales son motivo de otro estudio especial (perfil caracterológico de pacientes preparadas). (6)

\section{SICOPROFILAXIS OBSTETRICA}

Causas descondicionantes del primer período del parto

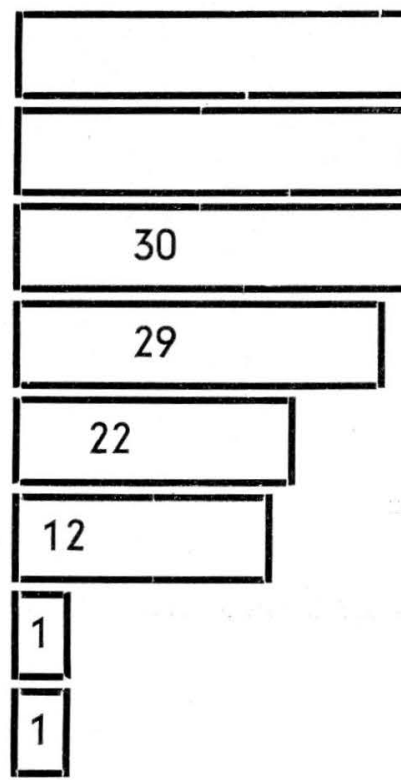

Lumbalgia

Temor

Fatiga

Vómito

Calambres

Distocia por incoordinación

Conocimiento de sufrimiento fetal

\section{CUADRO $\mathrm{N}^{0} 7$}

V Causas de descondicionamiento (cuadro $\mathrm{N}^{0}$ 7) en 1er. Período

Con el objeto de poder aclarar más aún cual fue la causa directa de descondicionamiento analizamos las que a juicio de la 
paciente y el obstetra, fueron las culpables de él. Así encontramos en este primer período el dolor en cincuenta y ocho casos, la lumbalgia en treinta y tres y el temor en treinta como los principales; en segundo plano de importancia la fatiga en casos de larga duración el vómito y los calambres los que ocuparon lugar destacado. Por último, aquellos casos cuyo trabajo se vio interferido por fenómenos de incoordinación contráctil demostrada o por el conocimiento de parte de la madre de signos de sufrimiento fetal, que terminaron en fracaso.

\section{SICOPROFILAXIS OBSTETRICA}

Causas descondicionantes del segundo período del parto

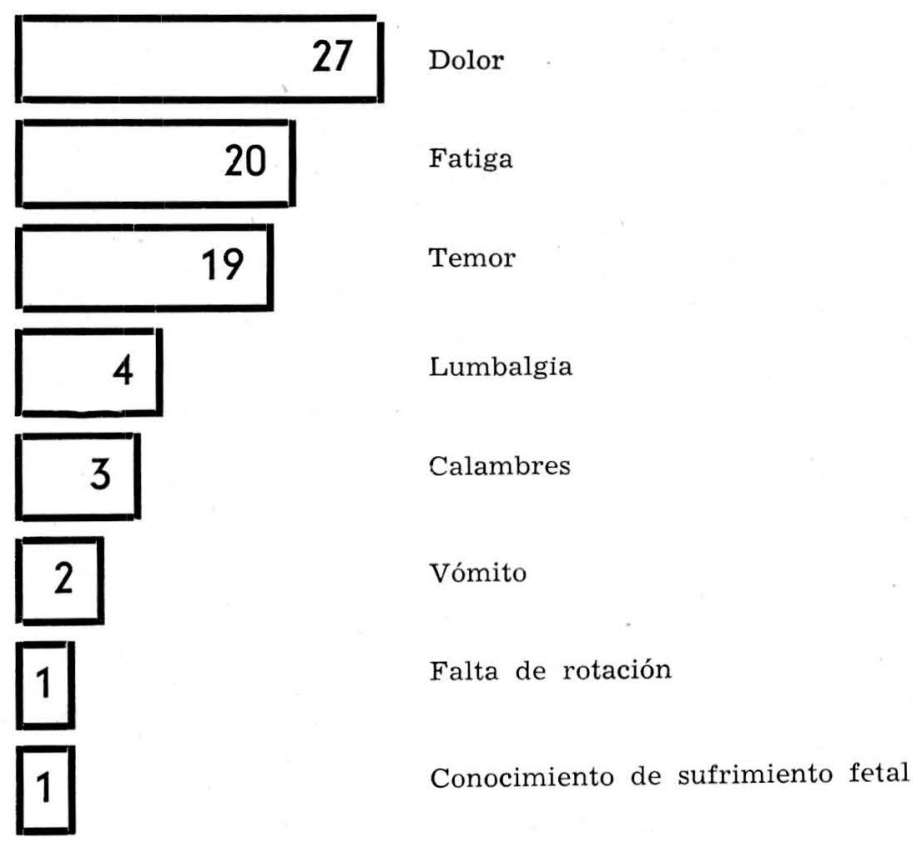

\section{CUADRO No 8}

b) En el Segundo Período (cuadro No 8)

Durante el período expulsivo el dolor fue en un alto porcentaje la causa primera, seguida de fatiga y temor. Las demás causas son notoriamente inferiores en frecuencia y su aparición coincidió con las del primer período. 


\section{SICOPROFILAXIS OBSTETRICA}

\section{Estudio de fracasos}

\section{Momento del parto en el cual se presentó el descondicionamiento}

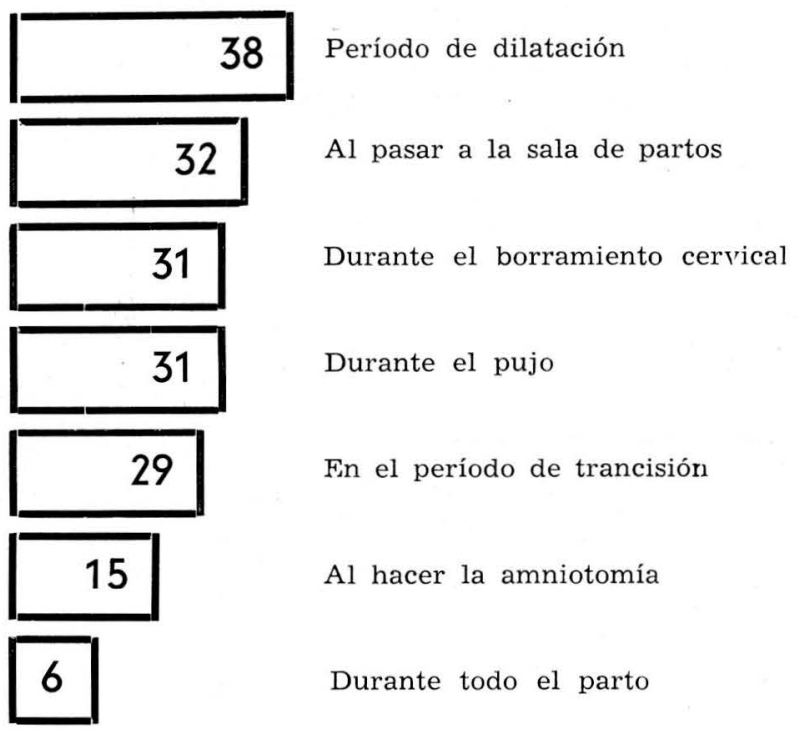

CUADRO No 9

VI Momento del descondicionamiento (cuadro $\mathrm{N}^{\circ}$ 9)

Pareciéndonos de una importancia enorme conocer en qué momento la paciente flaqueó y en qué proporción entre los casos estudiados, tenemos el cuadro $\mathrm{N}^{0} 9$ en el cual los porcentajes son altos para período de dilatación; (paso a la sala de partos, borramiento y pujo). Notándose que existen muchos casos en los cuales el descondicionamiento se hizo presente en casi todo el tiempo que duró el parto motivo por el cual fue imposible establecer índices absolutos. 
VII Duración del parto y descondicionsmiento (cuadro $\mathrm{N}^{\circ} \quad 10$ ) Duración del 1er. Período

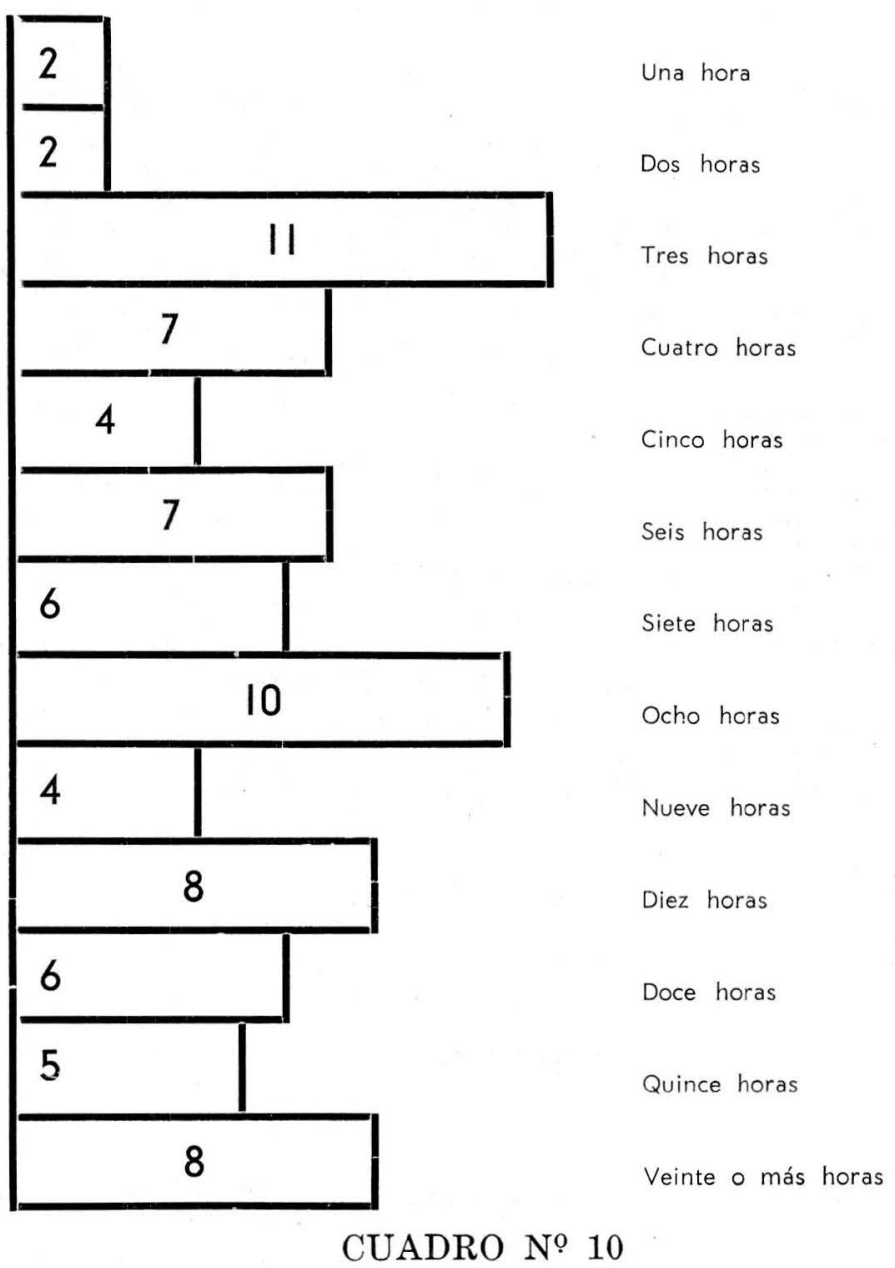

Con la intuición dada por la observación de casos aislados, en los cuales a mayor duración mayor descondicionamiento, emprendimos el estudio de la duración de cada uno de los períodos en nuestras historias de fracaso, y encontramos (cuadro $\mathrm{N}^{\circ}$ 10) que en el primer período no se halló una correlación clara entre el tiempo y el número de fracasos pues apreciándose un gran número de 3 y 4 horas de duración, también encontramos casos de 8,10 y 20 horas. 
Duración del $2^{\circ}$ Periodo (en minutos)

\section{3}

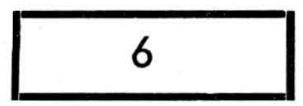

\section{3}

\section{1}

2

\section{CUADRO No 11}

15 minutos

20 minutos

30 minutos

45 minutos

60 minutos

120 minutos o más

En cambio, en lo relacionado con la duración de período expulsivo, sí encontramos tal correlación notándose una marcada tendencia al descondicionamiento y fracaso en casos que duraron más de 15 minutos.

SICOPROFILAXIS OBSTETRICA

Estudio de fracasos

Cuadro comparativo de las causas

4 Causas debidas a condiciones de vida

5 Causas debidas a condiciones ambientales

I5 Causas debidas al personal médico y asistencial

\section{$|5|$}

Causas intrínsecas debidas a la mujer misma 
Presentamos un estudio llevado a cabo sobre ochenta historias de fracaso del método sicoprofiláctico, tomados de series de pacientes privadas atendidas en la Clínica Palermo de Bogotá. Se dividieron en cinco las causas de fracaso de acuerdo con una clasificación propuesta en comunicación previa. (1)

a) Causas debidas al experimentador.

b) Causas ambientales.

c) Causas atribuíbles a condiciones de vida de las e nbarazadas.

d) Causas relacionadas con los tipos nerviosos.

e) Causas intrínsecas (debidas a la misma mujer). Estas últimas analizadas desde el punto de vista obstétrico, sicológico y físico.

Las conclusiones que obtuvimos son basadas en el cuadro comparativo de frecuencia (cuadro $\mathrm{N}^{0}$ 12), en el que observamos que a pesar de tener importancia grande las causas ambientales y de parte del experimentador, la mayor cantidad de causas de fracaso halladas en una proporción de 1/10 son debidas a la paciente misma, y en un alto grado a las de orden obstétrico y sicológico.

En esta forma, las inducciones, conducciones, distocias de rotación, antecedentes o perspectivas de cesárea, tal vez nó como causas directas sino a través de componentes neuróticos, no suficientemente controlados, son las más notorias causas, de descondicionamiento y de posterior fracaso.

Aclaramos que aquelles casos cuyo control fue excelente durante todo el trabajo y que por una causa obstétrica absoluta 0 relativa o bien por capricho de la paciente o fatiga del obstetra recibieron anestesia general en el último estado de su parto, tal vez podrían ser tomados como casos de fracaso parcial, no mencionables únicamente por el hecho de haber recibido anestesia general en forma innecesaria. 
Resaltamos por último la importancia del factor sicológico, aclarando que día a día al corregir los errores ya conocidos, podremos dar como descontado el descondicionamiento de toda mujer que desee ser atendida por el método, que ha tenido un entrenamiento físico y sicológico apropiado y que necesariamente debe dar lugar a un caso excelente.

\section{BIBLIOGRAFIA}

1 C. R. SILVA-MOJICA y M. A. FERNANDEZ-BASTIDAS. "Causas de fracaso en sicoprofilaxis Obstétrica". Rev Col. Obst. y Ginec. 11. (6) 867 1960. Bogotá.

2 FERNANDEZ-BASTIDAS M. A. "Analgesia obstétrica por métodos sicofísicos". Obst. y Ginec. Lat-Amer. 17-360. 199. Buenos Aires. Argentina.

3 SILVA-MOJICA C. R., FERNANDEZ-BASTIDAS M. A. Rev. Col. de Obst. y Ginec. 8-6 307. 1957. Bogotá.

4 Calderon Belisario. Rev. Col. de Obst. y Ginec. 8-6, 341. 1957.

5 SILVA-MOJICA C. R. y FERNANDEZ-BASTIDAS M. A. Rev. Col. Obst. y Ginec. 11. 144 1960. Bogotá.

6 RESTREPO BERTHA. "Perfil caracterológico de pacientes preparadas". Trabajo inédito presentado por EMESFAO al Tercer Simposio de Sicoprofilaxia Obstétrica de Bucaramanga.

7 Conclusiones del Primer Simposio Colombiano de Sicoprofilaxis Obstétrica celebrado en Bogotá. 1959. 